\title{
Effects of head-down tilt on intrapulmonary shunt fraction and oxygenation during one-lung ventilation in the lateral decubitus position
}

\author{
Yong Seon Choi, MD, ${ }^{a}$ Sou Ouk Bang, MD, a,b Jae Kwang Shim, MD, ${ }^{a, b}$ Kyung Young Chung, MD, PhD, ${ }^{d}$ \\ Young Lan Kwak, MD, PhD, ${ }^{\mathrm{a}, \mathrm{b}, \mathrm{c}}$ and Yong Woo Hong, MD, PhD ${ }^{\mathrm{a}, \mathrm{b}, \mathrm{c}}$
}

From the Department of Anesthesiology and Pain Medicine, ${ }^{a}$ Anesthesia and Pain Research Institute, ${ }^{\mathrm{b}}$ Yonsei Cardiovascular Research Institute, ${ }^{\mathrm{c}}$ and Department of Thoracic and Cardiovascular Surgery, ${ }^{\mathrm{d}}$ Yonsei University College of Medicine, Seoul, South Korea.

Received for publication Feb 24, 2007; revisions received April 24, 2007; accepted for publication May 11, 2007.

Address for reprints: Yong Woo Hong, $\mathrm{MD}, \mathrm{PhD}$, Department of Anesthesiology and Pain Medicine and Anesthesia and Pain Research Institute, Yonsei University College of Medicine, 134 Shinchon-Dong, Seodaemun-Ku, Seoul, South Korea, 120-725 (E-mail: ywhong@yumc.yonsei. ac.kr).

J Thorac Cardiovasc Surg 2007;134:613-8

$0022-5223 / \$ 32.00$

Copyright () 2007 by The American Association for Thoracic Surgery

doi:10.1016/j.jtcvs.2007.05.018
Objective: During one-lung ventilation, surgical positions significantly affect deterioration of oxygenation, and the lateral decubitus position is superior in preventing dangerous hypoxemia compared with the supine position. However, additional head-down tilt causes more compression of the dependent ventilated lung by the abdominal contents and may result in dangerous hypoxemia, as occurs in the supine position. Therefore, we evaluated the effect of head-down tilt on intrapulmonary shunt and oxygenation during one-lung ventilation in the lateral decubitus position.

Methods: Thirty-four patients requiring one-lung ventilation were randomly allocated to the control group $(\mathrm{n}=17)$ or the head-down tilt group $(\mathrm{n}=17)$. Hemodynamic and respiratory variables were measured 15 minutes after one-lung ventilation in the lateral decubitus position (baseline), 5 and 10 minutes after a 10-degree head-down tilt ( $\mathrm{T} 5$ and $\mathrm{T} 10$, respectively), and 10 minutes after the patient was returned to a horizontal position (T20) in the head-down tilt group. Measurements were done at the same time points in the control group without head-down tilting.

Results: In the head-down tilt group, cardiac filling pressures were increased after head-down tilt without any changes in cardiac index. Percent change of shunt to baseline value was significantly increased at T10 and T20 in the head-down tilt group. Percent change of arterial oxygen tension to baseline value was significantly decreased at T5, T10, and T20 in the head-down tilt group, whereas it was decreased only at T20 in the control group.

Conclusion: Head-down tilt during one-lung ventilation in the lateral decubitus position caused a significant increase in shunt and a decrease in percent change of arterial oxygen tension, without causing dangerous hypoxemia.

$\mathrm{D}$ uring thoracic surgeries requiring one-lung ventilation (OLV), deterioration of oxygenation is of major concern. Arterial oxygen tension $\left(\mathrm{PaO}_{2}\right)$ decreases progressively with time toward a steady value after the start of OLV that corresponds to the pulmonary shunt of deoxygenated blood through the nonventilated lung and to the ratio of ventilation and perfusion (V/Q) in the ventilated lung. ${ }^{1,2}$ Surgical positions considerably influence the deterioration speed and the nadir value of $\mathrm{PaO}_{2}$ after the start of $\mathrm{OLV}{ }^{3}$ In the supine position, dangerous hypoxemia $\left(\mathrm{PaO}_{2}<60 \mathrm{~mm} \mathrm{Hg}\right)$ occurred even after 10 minutes of OLV, and the lateral decubitus position was superior in preventing the occurrence of dangerous hypoxemia. ${ }^{3}$ In thoracic surgery with OLV in the lateral decubitus position, headdown tilt is sometimes necessary to optimize surgical exposure, especially in lower lobectomy by video-assisted thoracoscopic surgery (VATS) and posterior mediastinum surgery. However, this causes more compression of the dependent ventilated lung by the abdominal contents against the paralyzed diaphragm and may result in 

Abbreviations and Acronyms
$\mathrm{A}-\mathrm{aO}_{2}=$ alveolar-arterial $\mathrm{O}_{2}$ gradient
$\mathrm{CI}=$ cardiac index
$\mathrm{CVP}=$ central venous pressure
HPV = hypoxic pulmonary vasoconstriction
MAP $=$ mean arterial pressure
OLV = one-lung ventilation
$\mathrm{PAO}_{2}=$ alveolar oxygen tension
$\mathrm{PaO}_{2}=$ arterial oxygen tension
PVRI = pulmonary vascular resistance index
VATS $=$ video-assisted thoracoscopic surgery
$\mathrm{V} / \mathrm{Q}=$ ventilation and perfusion

increased intrapulmonary shunt and dangerous hypoxemia, as occurs in the supine position. Also, head-down tilt is often considered the first step to treat hemodynamically unstable patients when hypovolemia is suspected in clinical practice. However, the effects of this maneuver on cardiopulmonary performance remain controversial, ${ }^{4-12}$ especially in the lateral decubitus position. Therefore, we evaluated the effect of head-down tilt on intrapulmonary shunt and oxygenation and on hemodynamics during OLV in the lateral decubitus position in a prospective, randomized, controlled trial.

\section{Materials and Methods}

After patients' consent and institutional review board approval were obtained, 34 patients scheduled for open thoracotomy or VATS requiring OLV under general anesthesia were included in the study. Patients were randomly allocated to the 10-degree head-down tilt group or the control group by a computerized randomization table. Patients with coronary artery occlusive disease, high intraocular pressure, and cerebrovascular disease were excluded. Patients with preoperative forced expiratory volume in 1 second and forced vital capacity less than $80 \%$ of predicted value were also excluded.

On arrival at the operating room, standard monitoring devices were applied. Anesthesia was induced with $5 \mathrm{mg} / \mathrm{kg}$ of thiopental and $2 \mu \mathrm{g} / \mathrm{kg}$ of fentanyl. Endobronchial intubation with a leftsided, double-lumen tube (Robertshaw tube, Mallinckrodt Medical Inc, Athlone, Ireland) was facilitated with $0.9 \mathrm{mg} / \mathrm{kg}$ of rocuronium, and the position of the double-lumen tube was verified with a fiberoptic bronchoscope. After induction of anesthesia, a radial artery catheter was placed and a pulmonary artery catheter (SwanGanz CCOmbo $\mathrm{CCO} / \mathrm{SvO}_{2}$, Edwards Lifesciences LLC, Irvine, Calif) was inserted through the right internal jugular vein. The patients' lungs were ventilated with a tidal volume of 8 to 10 $\mathrm{mL} / \mathrm{kg}$, an inspiratory/expiratory ratio of $1: 1.9$, and an inspiratory pause of $10 \%$ of total inspiration time at a rate of 8 to 12 breaths/min in $100 \%$ oxygen with no positive end-expiratory pressure throughout the study period. The accordance of $\mathrm{PaCO}_{2}$ with end-tidal $\mathrm{CO}_{2}$ was confirmed before starting the study, and respiratory rate was adjusted to maintain $\mathrm{PaCO}_{2}$ within 33 to $38 \mathrm{~mm} \mathrm{Hg}$ and $\mathrm{pH}$ at approximately 7.4. Anesthesia was maintained with isoflurane $(0.8 \%-1 \%)$, continuous infusion of remifentanil (0.05$0.2 \mu \mathrm{g} / \mathrm{kg} / \mathrm{min}$ ), and vecuronium (1-2 $\mu \mathrm{g} / \mathrm{kg} / \mathrm{min})$. The central temperature measured by pulmonary artery catheter was maintained at greater than $36^{\circ} \mathrm{C}$ with a warm mattress, forced warm air blanket, and fluid warmer as necessary.

All patients were turned to the lateral decubitus position, OLV was initiated, and tidal volume and respiratory rate were adjusted within the predefined range to maintain peak airway pressure less than $40 \mathrm{~cm} \mathrm{H}_{2} \mathrm{O}$ and normocarbia. Fifteen minutes later, patients were positioned in a 10-degree head-down tilt for 10 minutes and then returned to the horizontal position in the head-down tilt group, whereas the control patients remained horizontal throughout the study period. Ten degrees was chosen because it was the most frequently used degree of tilting in most of the clinical cases as measured with a goniometer in a preliminary study. The pressure transducers were located at the level of the right atrium during all phases of the study and recalibrated after each position change. Arterial blood samples were measured with an automated blood gas analyzer (Stat Profile CCX, Nova Biomedical, Waltham, Mass).

Hemodynamic variables, arterial and mixed venous blood gas analyses, peak airway pressure, and dynamic pulmonary compliance were recorded at the following points. In the head-down tilt group, measurements were done at 5 minutes after induction of anesthesia, 15 minutes after OLV in the lateral decubitus position (baseline), 5 and 10 minutes after 10-degree head-down tilt (T5 and $\mathrm{T} 10$, respectively), and 10 minutes after the patient was returned to the horizontal position (T20). In the control group, measurements were done at the same time points while the patients remained horizontal in the lateral decubitus position. Hemodynamic measurements included mean arterial pressure (MAP), central venous pressure (CVP), pulmonary capillary wedge pressure, and cardiac index $(\mathrm{CI})$. Corresponding systemic vascular resistance index and pulmonary vascular resistance index (PVRI) were calculated using standard formulae. Oxygen content $\left(\mathrm{CxO}_{2}\right)$ in arterial and mixed venous blood was calculated using the equation: $\mathrm{CxO}_{2}=1.36 \cdot \mathrm{Hb} \cdot \mathrm{SxO}_{2}+0.0031 \cdot \mathrm{PxO}_{2}$, where $\mathrm{Hb}=$ hemoglobin concentration (grams/deciliter) and $\mathrm{SxO}_{2}=$ oxygen saturation. The alveolar-arterial $\mathrm{O}_{2}$ gradient $\left(\mathrm{A}-\mathrm{aO}_{2}\right)$ was calculated as the difference between alveolar oxygen tension $\left(\mathrm{PAO}_{2}\right)$ and $\mathrm{PaO}_{2}$. The intrapulmonary shunt was determined using the formula: shunt $=\left(\mathrm{CcO}_{2}-\mathrm{CaO}_{2}\right) /\left(\mathrm{CcO}_{2}-\mathrm{CvO}_{2}\right), \mathrm{CcO}_{2}=$ capillary $\mathrm{O}_{2}$ content calculated assuming that pulmonary capillary $\mathrm{O}_{2}$ partial pressure is equal to $\mathrm{PAO}_{2} \cdot{ }^{13}$ Percent change of shunt, $\mathrm{PaO}_{2}$, and $\mathrm{A}-\mathrm{aDO}_{2}$ from the baseline values were calculated as follows: (value at a given point - baseline value) $* 100 /$ (baseline value).

This study was planned to terminate if MAP decreased more than $20 \%$ of postinduction value, requiring vasoactive drug administration or $\mathrm{SpO}_{2}$ as measured by pulse oximetry declined to less than $90 \%$, or if $\mathrm{PaO}_{2}$ decreased less than $60 \mathrm{~mm} \mathrm{Hg}$. To control factors affecting hypoxic pulmonary vasoconstriction (HPV), any use of vasoactive drugs and surgical incision were withheld until after completion of study.

Statistical analyses were performed with the Statistical Package for the Social Sciences 12.0 (SPSS Inc, Chicago, Ill). All data are expressed as mean \pm standard deviation or number of patients. Because there was no previous study evaluating the effect of head-down tilt during OLV in the lateral decubitus position in 
TABLE 1. Patient characteristics

\begin{tabular}{lccc}
\hline & $\begin{array}{c}\text { Control } \\
(\mathbf{n}=\mathbf{1 7})\end{array}$ & $\begin{array}{c}\text { Head-down tilt } \\
(\mathbf{n}=\mathbf{1 7})\end{array}$ & $\boldsymbol{P}$ value \\
\hline Age (y) & $52.7 \pm 13.6$ & $53.9 \pm 9.0$ & .757 \\
Sex (M/F) & $10 / 7$ & $13 / 4$ & .465 \\
Body mass index $\left(\mathrm{kg} / \mathrm{m}^{2}\right)$ & $23.7 \pm 2.9$ & $23.4 \pm 2.3$ & .815 \\
FVC (\% as predicted) & $95.8 \pm 11.9$ & $92.7 \pm 15.1$ & .519 \\
FEV $1 \%$ as predicted) & $99.3 \pm 16.1$ & $102.4 \pm 18.6$ & .614 \\
Hemoglobin (g/dL) & $11.6 \pm 1.1$ & $12.3 \pm 0.7$ & .063 \\
Operative side (R/L) & $13 / 4$ & $9 / 8$ & .282 \\
\hline
\end{tabular}

$F V C$, Forced vital capacity; $F E V_{1}$, forced expiratory volume in 1 second. Values are mean $\pm S D$ or number of patients.

patients undergoing thoracic surgery, sample-size calculation was performed on the basis of a preliminary study with the following assumptions: $80 \%$ power to detect a $10 \%$ difference in percent change of $\mathrm{PaO}_{2}$ from baseline value between the groups with a standard deviation of $10 \%$ and an alpha level of 0.05 using an independent $t$ test. This generates an estimate of 17 patients each group. Data between the groups were compared using the chisquare test, Fisher exact test, or independent $t$ test as appropriate. Changes between time points within the group were compared using univariate analysis of variance with post hoc comparisons using the Dunnett test.

\section{Results}

The patients in the 2 groups were similar with respect to age, sex, body mass index, functional vital capacity, and $\mathrm{Hb}$ values (Table 1). The diagnoses of the patients were primary lung cancer (25 patients), lung metastases (6 patients), thymoma (2 patients), and endobronchial tuberculosis (1 patient). The surgical interventions that had been performed were pneumonectomy (2 patients), lobectomy (21 patients), wedge resection ( 8 patients), and VATS (3 patients).

None of the patients demonstrated dangerous hypoxemia or hypotension requiring vasoactive drugs, and the study was successfully performed in all patients. There were no significant differences in baseline hemodynamic and respiratory variables between the groups (Tables 2 and 3).

In intergroup comparisons of hemodynamic variables, CVP at T5 $(P=.019)$ and PVRI at T5 $(P=.044)$ and T10 $(P=.028)$ were significantly higher in the head-down tilt group. Other variables were similar.

In intragroup comparisons of hemodynamic variables to baseline values, CVP at T5 $(P=.003)$ and T10 $(P=.007)$, and pulmonary capillary wedge pressure at T10 $(P=.01)$ were significantly increased compared with baseline values and returned to baseline values at T20 in the head-down tilt group. Heart rate, MAP, CI, and systemic vascular resistance index were maintained during the study period in the

TABLE 2. Changes in hemodynamic variables

\begin{tabular}{|c|c|c|c|c|}
\hline Group & Baseline & T5 & T10 & T20 \\
\hline \multicolumn{5}{|l|}{ HR (beats/min) } \\
\hline Control & $68 \pm 9$ & $67 \pm 9$ & $66 \pm 9$ & $66 \pm 11$ \\
\hline Head-down tilt & $61 \pm 19$ & $64 \pm 11$ & $63 \pm 11$ & $63 \pm 12$ \\
\hline \multicolumn{5}{|l|}{ MAP (mm Hg) } \\
\hline Control & $83 \pm 9$ & $84 \pm 9$ & $85 \pm 8$ & $87 \pm 10$ \\
\hline Head-down tilt & $83 \pm 9$ & $87 \pm 9$ & $87 \pm 15$ & $82 \pm 10$ \\
\hline \multicolumn{5}{|l|}{ PCWP (mm Hg) } \\
\hline Control & $9.0 \pm 2.9$ & $10.5 \pm 3.2$ & $10.7 \pm 2.1$ & $10.7 \pm 2.7$ \\
\hline Head-down tilt & $8.8 \pm 3.1$ & $11.1 \pm 2.7$ & $11.8 \pm 3.8^{*}$ & $10.1 \pm 1.9$ \\
\hline \multicolumn{5}{|l|}{ CVP $(\mathrm{mm} \mathrm{Hg})$} \\
\hline Control & $4.9 \pm 2.7$ & $5.4 \pm 2.6$ & $5.7 \pm 2.5$ & $5.9 \pm 2.5$ \\
\hline Head-down tilt & $4.8 \pm 2.7$ & $7.6 \pm 2.8^{*} \dagger$ & $7.5 \pm 2.6^{*}$ & $5.2 \pm 1.3$ \\
\hline \multicolumn{5}{|l|}{$\mathrm{Cl}\left(\mathrm{L} / \mathrm{min} / \mathrm{m}^{2}\right)$} \\
\hline Control & $3.2 \pm 0.6$ & $3.1 \pm 0.6$ & $3.2 \pm 0.6$ & $3.3 \pm 0.8$ \\
\hline Head-down tilt & $2.9 \pm 0.6$ & $3.0 \pm 0.6$ & $3.1 \pm 0.7$ & $3.1 \pm 0.7$ \\
\hline \multicolumn{5}{|c|}{ SVRI (dynes $\cdot \mathrm{sec} \cdot \mathrm{cm}^{-5} \cdot \mathrm{m}^{2}$ ) } \\
\hline Control & $2033 \pm 411$ & $2074 \pm 382$ & $2067 \pm 411$ & $2076 \pm 565$ \\
\hline Head-down tilt & $2133 \pm 451$ & $2147 \pm 480$ & $2110 \pm 521$ & $2049 \pm 505$ \\
\hline \multicolumn{5}{|c|}{ PVRI (dynes $\cdot \mathrm{sec} \cdot \mathrm{cm}^{-5} \cdot \mathrm{m}^{2}$ ) } \\
\hline Control & $140 \pm 33$ & $145 \pm 30$ & $139 \pm 35$ & $147 \pm 38$ \\
\hline Head-down tilt & $169 \pm 61$ & $176 \pm 52 \dagger$ & $173 \pm 50 \dagger$ & $158 \pm 50$ \\
\hline
\end{tabular}

$H R$, Heart rate; $M A P$, mean arterial pressure; PCWP, pulmonary capillary wedge pressure; CVP, central venous pressure; $C l$, cardiac index; $S V R I$, systemic vascular resistance index; $P V R I$, pulmonary vascular resistance index. Values are mean \pm SD. Baseline, 15 minutes after initiation of OLV; T5, 5 minutes after head-down tilt; T10, 10 minutes after head-down tilt; T20, 10 minutes after horizontal position following head-down tilt. ${ }^{*} P<.05$ versus baseline in each group; $\uparrow P<.05$ versus control group. 
TABLE 3. Changes in respiratory variables

\begin{tabular}{|c|c|c|c|c|c|}
\hline Variable & Group & Baseline & T5 & T10 & T20 \\
\hline \multirow[t]{2}{*}{$\mathrm{PaO}_{2}(\mathrm{~mm} \mathrm{Hg})$} & Control & $309 \pm 54$ & $307 \pm 56$ & $307 \pm 55$ & $290 \pm 52$ \\
\hline & Head-down tilt & $299 \pm 49$ & $279 \pm 47$ & $279 \pm 47$ & $272 \pm 46$ \\
\hline \multirow[t]{2}{*}{$\%$ change of $\mathrm{PaO}_{2}$} & Control & & $-0.7 \pm 5.3$ & $-0.9 \pm 7.1$ & $-6.5 \pm 10.0^{*}$ \\
\hline & Head-down tilt & & $-6.3 \pm 6.7^{*} \dagger$ & $-6.4 \pm 7.8^{*} \dagger$ & $-6.8 \pm 8.8^{*}$ \\
\hline \multirow{2}{*}{$\mathrm{A}-\mathrm{aO}_{2}(\mathrm{~mm} \mathrm{Hg})$} & Control & $361 \pm 53$ & $364 \pm 56$ & $364 \pm 55$ & $384 \pm 51$ \\
\hline & Head-down tilt & $372 \pm 49$ & $391 \pm 48$ & $391 \pm 48$ & $400 \pm 46$ \\
\hline \multirow[t]{2}{*}{$\%$ change of $\mathrm{A}-\mathrm{aO}_{2}$} & Control & & $0.7 \pm 5.1$ & $1.1 \pm 6.9$ & $7.6 \pm 11.3^{*}$ \\
\hline & Head-down tilt & & $5.3 \pm 6.7 \dagger$ & $5.4 \pm 7.8$ & $6.4 \pm 8.3^{*}$ \\
\hline \multirow[t]{2}{*}{ Qs/Qt $(\%)$} & Control & $25.5 \pm 7.3$ & $32.6 \pm 14.5$ & $29.5 \pm 13.5$ & $29.9 \pm 6.6$ \\
\hline & Head-down tilt & $21.9 \pm 3.0$ & $28.3 \pm 9.4$ & $30.8 \pm 16.9^{*}$ & $30.1 \pm 6.1$ \\
\hline \multirow{2}{*}{$\%$ change of $0 \mathrm{~s} / 0 \mathrm{t}$} & Control & & $29.3 \pm 60.7$ & $19.9 \pm 43.8$ & $22.5 \pm 28.0$ \\
\hline & Head-down tilt & & $28.9 \pm 33.8$ & $40.7 \pm 70.3^{*}$ & $41.8 \pm 29.5^{*}$ \\
\hline \multirow[t]{2}{*}{ PAW $\left(\mathrm{cmH}_{2} \mathrm{O}\right)$} & Control & $21 \pm 4$ & $21 \pm 4$ & $21 \pm 4$ & $22 \pm 4$ \\
\hline & Head-down tilt & $24 \pm 6$ & $25 \pm 6 \dagger$ & $25 \pm 6 \dagger$ & $24 \pm 5$ \\
\hline \multirow[t]{2}{*}{ Cdyn $\left(\mathrm{mL} / \mathrm{cmH}_{2} \mathrm{O}\right)$} & Control & $29 \pm 9$ & $29 \pm 6$ & $30 \pm 6$ & $30 \pm 6$ \\
\hline & Head-down tilt & $28 \pm 8$ & $27 \pm 6$ & $26 \pm 6$ & $28 \pm 7$ \\
\hline
\end{tabular}

$\mathrm{PaO}_{2}$, Arterial oxygen tension; $\mathrm{Q} s / \mathrm{Qt}$, pulmonary shunt fraction; $P A W$, peak airway pressure; $C d y n$, dynamic compliance. Values are mean \pm SD. Baseline, 15 minutes after initiation of OLV; T5, 5 minutes after head-down tilt; T10, 10 minutes after head-down tilt; T20, 10 minutes after horizontal position following head-down tilt; ${ }^{*} P<.05$ versus baseline in each group; $\uparrow P<.05$ versus control group.

head-down tilt group. In the control group, there were no significant changes throughout the study period (Table 2).

In intergroup comparisons of respiratory variables, there were no significant differences in the absolute values of $\mathrm{PaO}_{2}, \mathrm{~A}-\mathrm{aO}_{2}$, and shunt. Percent $\mathrm{PaO}_{2}$ was significantly lower in the head-down tilt group at T5 $(P=.013)$ and T10 $(P=.044)$. Percent $\mathrm{A}-\mathrm{aO}_{2}$ was significantly higher in the head-down tilt group at T5 $(P=.034)$. Percent shunt showed a trend toward higher percent shunt in the headdown tilt group at T20 $(P=.083)$ without statistical significance. Peak airway pressure was significantly higher at T5 $(P=.032)$ and T10 $(P=.023)$ in the head-down tilt group without any differences in dynamic pulmonary compliance (Table 3).

In intragroup comparisons of respiratory variables to baseline values, shunt was significantly increased at T10 $(P$ $=.041)$ only in the head-down tilt group. Percent $\mathrm{PaO}_{2}$ was significantly decreased at T20 $(P=.022)$ in the control group, whereas it was significantly decreased at T5 $(P=$ $.021)$, T10 $(P=.02)$, and T20 $(P=.017)$ in the head-down tilt group. Percent $\mathrm{A}-\mathrm{aO}_{2}$ was significantly increased at T20 in both groups $(P=.01$ in the control group; $P=.024$ in the head-down tilt group). Percent shunt was significantly increased at T10 $(P=.019)$ and T20 $(P=.026)$ only in the head-down tilt group. Peak airway pressure and dynamic pulmonary compliance did not show any significant changes in both groups (Table 3 ).

\section{Discussion}

In this prospective, randomized, controlled study assessing the effect of 10-degree head-down tilt for 10 minutes during
OLV in the lateral decubitus position on respiratory variables and cardiac performance, we observed a significant increase in percent shunt and a decrease in percent $\mathrm{PaO}_{2}$ without eliciting dangerous hypoxemia. The absolute values of shunt and $\mathrm{PaO}_{2}$ showed no significant changes except the shunt at T10 in the head-down tilt group, which was increased compared with baseline value. These changes were accompanied by increases in cardiac filling pressures without any significant changes in CI.

OLV is frequently used in thoracic surgeries, and in some patients, severe hypoxemia may occur, mandating implementation of other therapies to provide adequate oxygenation. The cause of hypoxemia during OLV is mainly an increase in intrapulmonary shunt through the nonventilated lung. The principle mechanism to achieve better V/Q matching is to reduce pulmonary perfusion in the nonventilated lung. In a previous study, the lateral decubitus position prevented life-threatening hypoxemia $(\mathrm{SpO} 2<90 \%)$ in $92 \%$ of the patients, which developed approximately 10 minutes after the start of OLV in $82 \%$ of patients in the supine position in anesthetized humans. ${ }^{3}$ Both HPV and gravity cooperate to reduce pulmonary blood flow in the nondependent lung, ${ }^{3}$ and gravity is an important factor for the redistribution of pulmonary perfusion with proportionally more blood flow in the dependent areas of a lung in the lateral decubitus position. ${ }^{14}$

Although the lateral decubitus position is safer than the supine position, placing anesthetized patients in this position results in significant V/Q mismatch. With mechanical ventilation, the expansion of the dependent lung is restricted by abdominal contents impinging on the diaphragm, result- 
ing in overventilation of the nondependent lung and underventilation of the dependent lung. This leads to loss of functional residual capacity, atelectasis, and decrease in compliance in the dependent lung. ${ }^{15-17}$ In thoracic surgery, head-down tilt is sometimes required for optimal surgical exposure during thoracoscopic procedures or in managing hemodynamic instability. In anesthetized and paralyzed patients in the lateral decubitus position, additional head-down tilt might aggravate cephalad displacement of the abdominal contents and cause a decrease in functional residual capacity, total lung capacity, and compliance, ${ }^{6}$ which impose the risk of dangerous hypoxemia on OLV, as in the supine position. However, no comprehensive data exist regarding the effect of head-down tilt on intrapulmonary shunt and oxygenation during OLV in the lateral decubitus position, and we observed that a 10-degree head-down tilt for 10 minutes during OLV in the lateral decubitus position resulted in a significant increase in percent shunt and a decrease in percent $\mathrm{PaO}_{2}$ without eliciting dangerous hypoxemia.

To minimize factors affecting HPV response, anesthetic agents (narcotic + inhalation agent) and acid-base status were controlled throughout the study period. In addition, surgical incision and vasoactive agents were also withheld. As our results indicate, additional head-down tilt during OLV in the lateral decubitus position caused a faster decrease in percent $\mathrm{PaO}_{2}$, a faster increase in percent $\mathrm{A}-\mathrm{aO}_{2}$, and a significant increase in percent shunt, which persisted after return to the horizontal lateral decubitus position. The shunt values at baseline are consistent with a previous study with anesthetized mechanically ventilated patients with $100 \%$ oxygen during OLV. ${ }^{18}$ The decrease in percent $\mathrm{PaO}_{2}$ at T20 (ie, 35 minutes after the onset of OLV) in the control group is consistent with the regression curve of $\mathrm{PaO}_{2}$ decrement after OLV start in the lateral decubitus position without head-down tilt. ${ }^{3}$ The results showing a further increase in percent shunt, which was somewhat higher in the head-down tilt group than in the control group, even after the patients were returned to the horizontal lateral decubitus position $(P=.083)$, and a faster decrease in percent $\mathrm{PaO}_{2}$ in the head-down tilt group, which also has intergroup statistical significance, clearly indicate the impact of head-down tilt on these parameters. The effect of head-down tilt on these results could be attributable to a combination of multiple factors aggravating V/Q mismatch. Possible factors are as follows. First, increased atelectasis formation by the impingement of abdominal contents against the paralyzed diaphragm should be considered. It has been demonstrated that the magnitude of shunt correlates to the size of atelectasis. ${ }^{19}$ Second, although gravity, rather than HPV response, was suggested to be a more dominant factor in the distribution of pulmonary perfusion in the lateral decubitus position, ${ }^{3}$ decreased HPV response should also be considered.
HPV response is maximal when pulmonary vascular pressure is normal and is decreased by high or low pulmonary vascular pressure. HPV response is induced not only by a decrease in $\mathrm{PAO}_{2}$ but also by a decrease in mixed venous oxygen tension, which under the same conditions reflects cardiac output. ${ }^{20}$ Because there were no significant differences in CI between the groups, increased peak airway pressure and PVRI in the head-down tilt group would cause a less-effective HPV response because the pulmonary circulation is poorly endowed with smooth muscle and cannot constrict against an increased vascular pressure. ${ }^{21}$ Because none of the patients demonstrated dangerous hypoxemia and neither of the absolute values of shunt or $\mathrm{PaO}_{2}$ showed clinically significant changes, the dominant role of gravity is indicated in the redistribution of pulmonary blood flow in the lateral decubitus position enhancing V/Q and thereby preventing the occurrence of dangerous hypoxemia.

The limitations of this study are as follows. First, the maximal HPV response in anesthetized humans in the supine position occurred within 15 minutes $^{22}$; however, the time of maximal HPV response during OLV in the lateral decubitus position has not been demonstrated. For ethical reasons, we confined the duration of head-down tilt to 10 minutes. The duration was set with regard to a finding from a previous study showing that $92 \%$ of patients demonstrated dangerous hypoxemia during OLV in the supine position in 10 minutes, ${ }^{3}$ and to limit the duration of delaying surgical procedure, which was withheld to minimize its influence on the HPV response. Therefore, the duration in this study might not be sufficient to have induced maximal HPV response. Unlike in the supine position, considering that HPV response seems to contribute only a minor portion in redistribution of pulmonary blood flow in the lateral decubitus position with a more dominant role of gravity, more prolonged duration of head-down tilt would not have resulted in better preservation of either percent shunt or percent $\mathrm{PaO}_{2}$. Second, to avoid distorting comparative outcome, we excluded patients with decreased pulmonary function (forced expiratory volume in 1 second and forced vital capacity $<80 \%$ ), who could be more susceptible to dangerous hypoxemia during OLV; therefore, these results should not be extended to this subset of patients.

\section{Conclusions}

Additional 10-degree head-down tilt for 10 minutes during OLV in the lateral decubitus position caused a significant increase in percent shunt that persisted after return to the horizontal lateral decubitus position, a faster decrease in percent $\mathrm{PaO}_{2}$, and a faster increase in percent $\mathrm{A}-\mathrm{aO}_{2}$. These changes were accompanied by transient increases in cardiac filling pressures without any changes in CI. However, none of the patients demonstrated dangerous hypoxemia, and the absolute values of shunt and $\mathrm{PaO}_{2}$ showed clinically insig- 
nificant changes between the groups. Therefore, brief periods of additional head-down tilt during OLV in the lateral decubitus position for optimizing surgical exposure are well tolerated in patients with preserved pulmonary function.

\section{References}

1. Guenoun T, Journois D, Silleran-Chassany J, Frappier J, D'attellis N, Salem A, et al. Prediction of arterial oxygen tension during one-lung ventilation: analysis of preoperative and intraoperative variables. J Cardiothorac Vasc Anesth. 2002;16:199-203.

2. Eisenkraft JB. Effects of anesthetics on the pulmonary circulation. $\mathrm{Br} J$ Anesth. 1990;65:63-78.

3. Watanabe S, Noguchi E, Yamada S, Hamada N, Kano T. Sequential changes of arterial oxygen tension in the supine position during one-lung ventilation. Anesth Analg. 2000;90:28-34.

4. Kardos A, Foldesi C, Nagy A, Saringer A, Kiss A, Kiss G, et al. Trendelenburg positioning does not prevent a decrease in cardiac output after induction of anaesthesia with propofol in children. Acta Anaesthesiol Scand. 2006;50:869-74.

5. Hirvonen EA, Nuutinen LS, Kauko M. Hemodynamic changes due to Trendelenburg positioning and pneumoperitoneum during laparoscopic hysterectomy. Acta Anaesthesiol Scand. 1995;39:949-55.

6. Wilcox S, Vandam LD. Alas, poor Trendelenburg and his position! A critique of its uses and effectiveness. Anesth Analg. 1988;67:574-8.

7. Terai C, Anada H, Matsushima S, Shimizu S, Okada Y. Effects of mild Trendelenburg on central hemodynamics and internal jugular vein velocity, cross-sectional area, and flow. Am J Emerg Med. 1995;13: 255-8.

8. Reich DL, Konstadt SN, Raissi S, Hubbard M, Thys DM. Trendelenburg position and passive leg raising do not significantly improve cardiopulmonary performance in the anesthetized patient with coronary artery disease. Crit Care Med. 1989;17:313-7.

9. Reuter DA, Felbinger TW, Schmidt C, Moerstedt K, Kilger E, Lamm $\mathrm{P}$, et al. Trendelenburg positioning after cardiac surgery: effects on intrathoracic blood volume index and cardiac performance. Eur $J$ Anaesthesiol. 2003;20:17-20.

10. Ostrow CL, Hupp E, Topjian D. The effect of Trendelenburg and modified Trendelenburg positions on cardiac output, blood pressure, and oxygenation: a preliminary study. Am J Crit Care. 1994;3:382-6.
11. Sing RF, O'Hara D, Sawyer MA, Marino PL. Trendelenburg position and oxygen transport in hypovolemic adults. Ann Emerg Med. 1994; 23:564-7.

12. Gentili DR, Benjamin E, Berger SR, Iberti TJ. Cardiopulmonary effects of the head-down tilt position in elderly postoperative patients: a prospective study. South Med J. 1988;81:1258-60.

13. Chow MY, Goh MH, Boey SK, Thirugnanam A, Ip-Yam PC. The effects of remifentanil and thoracic epidural on oxygenation and pulmonary shunt fraction during one-lung ventilation. $J$ Cardiothorac Vasc Anesth. 2003;17:69-72.

14. Ross DJ, Wu P, Mohsenifar Z. Assessment of postural differences in regional pulmonary perfusion in man by single-photon emission computerized tomography. Clin Sci (Lond). 1997;92:81-5.

15. Wulff KE, Aulin I. The regional lung function in the lateral decubitus position during anesthesia and operation. Acta Anaesthesiol Scand. 1972;16:195-205.

16. Rehder K, Sessler AD, Rodarte JR. Regional intrapulmonary gas distribution in awake and anesthetized-paralyzed man. J Appl Physiol. 1977;42:391-402.

17. Klingstedt C, Hedenstierna G, Lundquist H, Strandberg A, Tokics L, Brismar B. The influence of body position and differential ventilation on lung dimensions and atelectasis formation in anaesthetized man. Acta Anaesthesiol Scand. 1990;34:315-22.

18. Garutti I, Quintana B, Olmedilla L, Cruz A, Barranco M, Garcia de Lucas E. Arterial oxygenation during one-lung ventilation: combined versus general anesthesia. Anesth Analg. 1999;88:494-9.

19. Tokics L, Hedenstierna G, Strandberg A, Brismar B, Lundquist H. Lung collapse and gas exchange during general anesthesia: effects of spontaneous breathing, muscle paralysis, and positive end-expiratory pressure. Anesthesiology. 1987;66:157-67.

20. Domino KB, Wetstein L, Glasser SA, Lindgren L, Marshall C, Harken $\mathrm{A}$, et al. Influence of mixed venous oxygen tension (PVO2) on blood flow to atelectatic lung. Anesthesiology. 1983;59:428-34.

21. Benumof JL. One-lung ventilation and hypoxic pulmonary vasoconstriction: implications for anesthetic management. Anesth Analg. 1985; 64:821-33

22. Bindslev L, Jolin A, Hedenstierna G, Baehrendtz S, Santesson J. Hypoxic pulmonary vasoconstriction in the human lung: effect of repeated hypoxic challenges during anesthesia. Anesthesiology. 1985; 62:621-5. 